\title{
Experiencing Transformative Learning: An Autoethnographic Journey through Ethical Dilemma Story Pedagogy (EDSP)
}

Kashiraj Pandey $(\mathrm{PhD})$

\begin{abstract}
I believe our cultural heritage has so much potential for creating new forms of knowing about the self, others, community, and environment while also revealing the interconnected spaces and realities that reside between cultures and people. The Nepalese heritage encompasses through a rich tradition of narratives in storying. For the purpose of present research, I composed two ethical dilemma stories and discussed them in classrooms with a critically reflective understanding of the subject matter where I utilised the local, lived contexts and characters from the Nepalese society. The results have shown that this study, with the use of ethical dilemma stories as a key tool to interact with the research participants, gave sufficient challenges and possibilities for transformative learning. Therefore, the aim of this paper is to explore the unification of my personal, professional, and cultural spheres that are focused on the importance of transformative learning using an autoethnographic methodology. The paper also tries to document my lived experiences through stories as the understanding of my own self, other selves, and cultures around me.
\end{abstract}

Key words: Autoethnography, Ethical Dilemma Story Pedagogy, Life History, Reflective Practice, Transformative Learning 


\section{Introduction}

Educators who seek to implement transformative perspectives are not confined to their classrooms. Transformative learning, according to Mezirow (2012, p. 76), refers to the process by which "we transform our taken-for-granted frames of reference to make them more inclusive, discriminating, open, emotionally capable of change, and reflective". Transformative learning inspires learners to reflect and review their existing values to reconstruct and shift these understandings; it involves continuously revisiting and revising assumptions from multiple points of view. It involves all aspects of "head, heart and hands" (Bruehlmeier, 2010), and training different sides of the brain; it is an approach closely related to self-participation, real-life application, learners' willingness to support each other, and to critically reflect in order to foster personal development and knowledge empowerment. Thus, transformative learning is about interruption and re-positioning assumptions, beliefs, values, practices and perspectives; it is a desire to change the way things are in order to imagine alternative possibilities.

As an autoethnographer, I have an unyielding commitment to connect education with my lived experiences in social and political contexts, and our daily lives filled with spirit, love and courage. Hence, I begin to see the potential of transformative learning through an autoethnographic methodology and try to demonstrate this connection through stories composed within cultures around me. Autoethnography is defined by Garance Marechal (2010) as an autobiography with a social-political interest. Marechal (2010, p. 44) adds that this mode of research serves as an 
effective approach based on one's self-critical reflection seeking to encompass one's:

... self-observation and reflexive investigation in the context of ethnographic field work and writing. The term [autoethnography] has a double sense, referring either to the reflexive consideration of a group to which one belongs as a native, member, or participant (ethnography of one's own group) or to the reflexive accounting of the narrator's subjective experience and subjectivity (autobiographical writing that has ethnographic interest). This distinction can be blurred in some research traditions.

Autoethnography is sometimes made synonymous with self-ethnography, reflexive ethnography, or performance ethnography, and can be associated with narrative inquiry and autobiography.

Autoethnography links our autobiographies, as windows for reflection, to the existing social contexts and motivates us towards refreshing performance and change. Autoethnography moves beyond the confines of conventional academic practices where short stories, poems, and our inward looking conversational scripts as self- narratives hold their prominent space during the research process and documentation. The major part of this paper, therefore, has been based on the narratives of my own becoming as a transformative learner as well as on the experiences of teaching two ethical dilemma stories in a Bachelor of Education (B.Ed.) classroom. 


\section{Research Site and Participants}

I identified Mountain Multiple College, Nepal, as my research site which is situated 65 kilometres away from Kathmandu, and located in a rural setting. I chose B.Ed. students as research participants who were well-suited to my research project. I presented written information to the participants, which involved informing them of the aims, procedures, and their roles in the research, and my intention to allow them to make informed decisions about whether to participate in the research process. The participants came from different sociocultural and economic backgrounds. Although some students worked part-time in nearby private schools, the majority of them were pre-service teachers of English who aimed at finding a teaching position upon their graduation. They were selected for their knowledge, relationship and expertise with my research subject in such a method which belongs to the category of purposive selection techniques. The participants had a special relationship with the phenomenon under investigation, relevant to the nature of my research, and their active involvement in it. Yet, I was aware of the fact that not all who promise to join a project necessarily can attend the component sessions. The research participants included me (male) as teacher-researcher, the usual class teacher and four pre-service teachers, all enrolled in the B. Ed. English Language Teaching course. All participants regularly attended activities during the fieldwork teaching period and have remained in touch afterwards. 


\section{Reflection in Transformative Learning}

Some of the strategies I have sought to apply in this research are writing as inquiry, performativity of metaphoric languages, and literary images in multiple genres. My reflections are interwoven within the transformative contexts of my own lived experiences, as acknowledged by Connelly and Clandinin (1994, p. 155):

We imagine as we try to give accounts of our own lives that we undergo cultivation, awakenings, and transformations throughout our lives. People's lives are composed of many narrative unities, some of which, at any one time, may be thought of educationally in terms of cultivation, others in terms of awakening, and still others in terms of transformation.

This research undergirds my role, as a researcher, and my participants' real-life journey given our active involvement in the research based upon a mutually beneficial relationship. Life history in many ways resembles life-story and biography which William Tierney and Randall Clemens (2012, p. 266) clarify as, "[t]o one researcher, biography, life story and life history may be perfectly synonymous; to another interchanging the terms may indicate methodological laziness". When we include our biography in the research, it enables us to move towards thinking about our life history, toward the narrative of our own life worlds, toward our autobiography, and toward values and beliefs within our own cultural, socio-political contexts. Tierney and Clemens (2012, p. 270) further suggest that "the value of life history is to provide a portrait of lives over time". Things that we 
considered insignificant or even that are seen as overemotional at one point can have sufficient reason to be revisited and be useful to document as a literary or researchable record that can be meaningful for others to look at and reflect upon. Such writings have allowed me to reach near reality; and, the poetic logic has helped me to move away from the traditional, deductive way of understanding truth. Recalling my own school days 35 years ago in my village, I would walk to my school every day and attend classes in a regular basis. When our teachers found us on playground during the school hours, they would ask us to go back to our respective classrooms and read books even when the teachers stayed back in the office-room or played. Now, there are 'different students (or should I call them children?)' in many Nepalese village schools playing the role of us, the young children of those early days, and there are still a similar number of teachers, schools, books and the live like the ones we experienced. Such realization has allowed me to create an artistic cross-stitch and channel the tension between my past personal/professional memories and present understandings in writing.

Research into transformative learning requires a reflective mind and an awareness of the researcher's contribution to the construction of meanings throughout the research process. I recall Lev Vygotsky's (1978) ideas in social constructivism for the community-cultural contexts to play a vital role in our learning process. Learning is a process of adapting and creating meaning from human experience and interaction within the culturally shared ways of understanding the world. Our lived experiences carry meanings in context to situations. In this research, I have come across many emergent 
experiences where our "bodies, emotions, and lived experience [have] become texts to be written" (Gannon, 2018, p. 23). These personal experiences allow us to access the participants' day-to-day life including local culture and history and the ways in which these components constitute their identities in the learning. Although they may sound a bit excessive, issues such as cultural extinction, climate change and violence, are always productive for an educator to prepare young people for the challenges of a volatile and uncertain world. I argue that pivotal to this task is the need to create a new set of transformational tools capable of accommodating personal, social and political change.

\section{Ethical Dilemma Story Pedagogy (EDSP) in Transformative Learning}

The Ethical Dilemma Story Pedagogy has explored interpretative and creative spaces for transformative learning both personally and with the research participants. The use of ethical dilemma stories was employed to engage participants in learning based on personal values about particular aspects that had appeared in their lives. This experience has been the power of culturally appropriate and contextual pedagogy that also accounts my experience of transformative learning as a researcher and practitioner. The pedagogy describes the practical aspects of presenting ethical dilemma stories to participating pre-service teachers to see the impact of transformative learning. Edward Taylor and Patricia Cranton (2012, p. 5) acknowledge that "[t]ransformative learning theory is based on the notion that we interpret our experiences in our own way, and that how we see the world is a result of 
our perceptions of our experiences". The EDSP, as an active means of transformative learning, has encouraged learners to think about prior beliefs and biases that prompted their active participation in dealing with everyday issues, and to propose solutions to societal disparities. It can provide relatable scenarios to challenge and unsettle learners' thought processes leading to acknowledging multiple viewpoints. The EDSP also provides the context in which $\mathrm{I} /$ we engage in a transformative learning journey with the goal of prompting dialogue and educational change within Nepalese schools.

Previously, my way of thinking about education and research delivered in universities was limited to more traditional ways of being and knowing. I used to think that there was only one dominant paradigm of learning and research that had a set of central beliefs and norms to follow, which were disconnected from my life. On reading Mezirow's (2003, p. 58) work on transformative learning as discourse, I was encouraged to see teaching and learning as a process that "transforms problematic frames of reference - sets of fixed assumptions and expectations (habits of mind, meaning perspectives, mindsets), to make them more inclusive, discriminating, open, reflective, and emotionally able to change". This research provided me with opportunities to explore how teaching and learning might be more open to human curiosity, value-based awareness, and learners' natural passion (Mezirow, 2003). With this idea in mind, I sat quietly and reflected on how I listened to, and considered, the truth claims of experts and their appeal to science and objectivity. Then, I felt fortunate to have had the opportunity to come across an alternative transformative approach to research. This new approach allowed me to encounter places and people from 
diverse backgrounds and cultures which gave me the confidence to feel for myself, relish new challenges, and narrate them as my own form of knowledge production.

Juanita Johnson-Bailey and Mary Alfred (2006, p. 55) acknowledge how the majority of educators fail to make a connection between what they "claim they value and the values their practices demonstrate". Transformative learners, however, see an opportunity in every situation to conceptually construct knowledge from experience, negotiate meaning, and draw conclusions from a unique interpretation of the world. One constant message which came from the research participants, was that traditional ways of teaching and learning were not providing them with opportunities for transformative learning. In the successive research communications, participants shared the value of the ways in which ethical dilemma stories highlighted various contemporary social issues such as: democracy, freedom, sustainability, political chaos, remittances, family responsibilities, inter-personal behaviours, hygiene and cleanliness, enhancing food security, and dietary requirements of people of different ages in the community. This message demonstrates the importance of research of this nature where the ethical dilemma stories have strong resonance with local teaching and learning contexts. I also consider the essential values of the inner orientation of my autoethnographic research and the ways in which it has enabled me to develop a more critical orientation to my teaching and writing. Freire (1998, p. 31) comments on this realisation, saying: 
There is, in fact, no teaching without learning. One requires the other. And the subject of each, despite their obvious differences, cannot be educated to the status of object. Whoever teaches learns in the act of teaching, and whoever learns teaches in the act of learning.

Transformative learning seeks to develop constructive, learner-centred practices in the face-to-face classroom environment. It is about raising awareness so that "the learner understands that there is value in learning and appreciates the learning process" (Adams, 2007, p. 153). Therefore the format should be more learner-centred to elicit responses from students by drawing on their language, culture, experience and interests as the starting point for learning; it should not be: this is what you will learn.

The practice of critical reflection to create a more socially just world involves the realisation of mutual respect, collaboration, care, and trust. Although this research incorporates many personal truths from my own life, its findings will serve to inform other educators who wish to utilise socio-cultural contexts connected to students' lives as a transformative pedagogy in their learning process. In my role as a transformative educator, I have always been mindful of asking more reflective kinds of questions such as:

- Are the contents of my teaching relevant and meaningful to learners?

- To what extent am I learning from and producing knowledge with my students? 
- To what extent "am I [are we] willing to transform myself [ourselves] in the process of helping my [our] students transform" (Taylor, 2006, p. 92)?

When I wrote two ethical dilemma stories, "The dilemma of life and how we live" and "The dilemma of leaving home", for this research purpose, I was mindful in making both the stories appear realistic, and not complicating the narratives. I chose the easily relatable characters where the participants were able to connect themselves with the story characters during class discussions. They kept asking questions such as, "How do you come to know the story characters?; How long do you know them for?; Did they really leave the village (please, sir: Tell me)? Where are they now?" such questioning provided the proof that I was able to arouse curiosity while composing and telling the dilemma stories to the participants. I also found that the exposure opened reason for participants to actively communicate their ideas and concepts among each other in the classroom and even with their parents, family members, and other people outside their classrooms. The power of their simple words as valuable resources in relating to and potentiating their experiences, interests, and imaginations led our discussion towards thinking beyond the classroom, and relating to the world outside. Both the ethical dilemma stories had a strong influence on the imaginative activities of my participants.

During the research process, there were also some features of great importance, such as the participants' personal development, and their strong enthusiasm for their learning. These interactive elements allowed me to do things differently and vary the strategies. I realised that, for a successful 
learning experience for my students, as their teacher, I needed to be flexible and accommodating enough to familiarise changes according to their learning situations. Acknowleging that students are the true partners in the learning process, we need to raise our voices and move towards learner-centred, transformative approaches in which students are the central part of learning process. Transformative learning plays an active role in contrast to "the teacher-centred learning wherein the teacher remains at the centre of the learning process" (Sherine, 2015, p. 242). The EDSP has allowed the participating pre-service teachers to become more mutually collaborative, critically reflective, and emotionally mature as they gained the ability to show empathy and thoughtfulness. Interestingly the German root word for empathy is Einfuehlung, meaning feeling into/within for others (Simpson \& Weiner, 1989). This is especially pertinent for interaction between the reader and the characters in the dilemma stories. I believed that EDSP also afforded my participants opportunities to identify with the story characters and make decisions on the respective character's behalf. The participants often reported that this research experience, which was supported by their own activities, has changed their ways of thinking. All of them shared a similar experience; their reactions varied depending on personal context and connection. I was delighted to see that the participants were engaged in both the dilemma stories as I was initially uncertain of their reactions to this method. My present research, therefore, resonates with a rich tradition of transformative education.

I found EDSP a more dynamic experience where learning can emerge from students' own cultural contexts and knowledge 
can be fostered from their own critical self-awareness; the students know what they are doing. Similar responses of contemplation, reflection, and realisation have been reported by my participants, the pre-service teachers, in their interview responses as counter-narratives. The participants shared that they learnt more effectively when they were actively involved in the learning process and with their own local, cultural contexts. I have found that these participants were continuing to work hard to incorporate, into their own teaching, the transformative ideas about analytic discussions in class that they acquired from this research project. The participants formed study groups that met at regular times, as they were inspired by the benefit of sharing in my research, to help their students grow through cooperation and coordination. By doing this, the participants realised that working in a group and pairs helped their students to learn better than using the traditional teacher-centred, didactic methods. They shared that some part of the textbook that seemed confusing to one student could be quite clear to another student. Thus, the struggling students too learnt quickly by simply asking questions to their friends, instead of puzzling over the difficulty, spending much effort and time to solve it, or sometimes giving up. Also, their observation revealed that the smarter students enjoyed explaining their perspectives and gained confidence by helping other students to overcome their difficulties by reaffirming what they had already understood. The participants also shared that they exchanged their favourite stories, reflections, and study tricks in the topic discussed. Despite their prior beliefs, gender, ethnic background, and social class, all participants experienced a similar amount of learning. 
In this context, I reflect on my own self-interactive journey along with the experiences of my teaching of ethical dilemma stories to my research participants. They were en coursed to engage with EDSP which also opened the door for transformational opportunities. I hope this research will also encourage other researchers to bring their expertise to the table around a cultural-contextual topic that values learners' prior experience, their inherent orientation to critical approaches, empathy, and desire to change for the positive.

Hence, this research records my new understandings and insights about the benefits of transformative learning as evidenced by my own personal-professional growth and that of my participants. The present research, therefore, allowed us, myself and the research participants, to challenge some deeply embedded assumptions about teaching and learning for the purpose of revitalising our own professional judgments and practices. I am sure the ethical dilemma story pedagogy will be applied practically in future research to further refine the idea of transformative learning with new insights.

\section{Conclusion}

This research involved the task-oriented learning activities which provided opportunities for individual learners to communicate their desires, needs, feelings, and interests. The ethical dilemma learning experience was emotionally engaging to my participants. They themselves have developed skills beyond their disciplines while they interpreted and reinterpreted their experience with the issues they dealt with (Mezirow, 1991). In addition to taking the class and getting a grade, the research included a series of additional activities that encouraged the participants to reflect and realise who 
they are, how they have grown, what they have learnt and what they value. They have developed common meaning through reflection to better understand each other. The participants have effectively developed the ability to work cooperatively with others for a specific purpose, collaboratively as a team member. The participants' written and verbal communication skills allowed them to thoughtfully identify what information they need before they put the issues in discussion; they developed a good sense of empathy with the characters and local contexts.

'Practice makes perfect' is a shibboleth that appears valid in the case of the pedagogy I am seeking to advocate. In practice, I found the EDSP to be effective in aiding the students to express their ideas in coherent English propositional forms as a means of self-expression and of sharing ideas with classroom peers and with the teacher. The overall experience, indeed, became productive in helping the learners to connect their "individuality to larger historical and social issues; to encourage students to examine how their experience relates to academic knowledge, to power, and to inequality in society; and to approach received wisdom and the status quo with questions" (Shor, 1992, p. 16). This is goal of transformative learning pedagogy and I am sure such attributes have enabled the participats and myself to successfully reach our pedagogical goals. Now, I hope that further discussion of transformative learning in the classroom can have a positive inspiration in teaching English in Nepal, and, by extension, to other school subjects in many parts of the world. 


\section{References}

Adams, D. (2007). Lifelong learning skills and attributes: The perceptions of Australian secondary school teachers. Issues in Educational Research, 17(2), 149160.

Bruehlmeier, A. (2010). Head, heart and hand: Education in the spirit of Pestalozzi. Mike Mitchell (Trans.). Cambridge, UK: Open Book Publishers.

Connelly, M., \& Clandinin, J. (1994). Telling teaching stories. Teacher Education Quarterly, 21(1), 145-158.

Freire, P. (1998). Pedagogy of freedom: Ethics, democracy, and civic courage. Lanham, MD: Rowman \& Littlefiel.

Gannon, S. (2018). Troubling autoethnography: Critical, creative, and deconstructive approaches to writing. In S. Holman Jones \& M. Pruyn (Eds.), Creative selves/creative cultures: Critical autoethnography, performance, and pedagogy (Creativity, Education and the Arts) (pp. 21-35). doi: 10.1007/978-3-31947527-1_2

Johnson-Bailey, J., \& Alfred, M. (2006). Transformational teaching and the practices of black women adult educators. In E. W. Taylor (Ed.), Teaching for change: Fostering transformative learning in the classroom, 109 (pp. 49-58). San Francisco, CA: Jossey-Bass.

Marechal, G. (2010). Autoethnography. In Albert J. Mills, Gabrielle Durepos \& Elden Wiebe (Eds.), Encyclopedia of case study research (pp. 43-45). 
Thousand Oaks, CA: Sage. doi: http://dx.doi.org/10.4135/9781412957397.

Mezirow, J. (1991). Transformative dimensions of adult learning. San Francisco: Jossey-Bass.

Mezirow, J. (2003). Transformative learning as discourse. Journal of Transformative Education, 1(1), 58-63.

Mezirow, J. (2012). Learning to think like an adult: Core concepts of transformation theory. In E. Taylor, P. Cranton \& Associates (Eds.), The handbook of transformative learning (pp. 73-95). San Fransisco, CA: Jossey-Bass.

Sherine, A. (2015). Student centered learning a pedagogical advancement in higher education - A challenge for language teachers. IJELLS, 3(2), 242-251.

Shor, I. (1992). Empowering education: Critical teaching for social change. Chicago: The University of Chicago Press.

Simpson, J., \& Weiner, E. (1989). The Oxford English Dictionary. Oxford: Oxford University Press.

Taylor, E. W. (2006). The challenge of teaching for change. In E. W. Taylor (Ed.), Teaching for change: Fostering transformative learning in the classroom, 109 (pp. 9195). San Francisco, CA: Jossey-Bass.

Taylor, E. W., \& Cranton, P. (2012). The handbook of transformative learning: theory, research, and practice. San Francisco: Jossey-Bass.

Tierney, W.G., \& Clemens, R. (2012). The uses of life history. In Sara Delamont (Ed.), Handbook of 
qualitative research in Education (pp. 265-281). Cheltenham, UK: Edward Elgar.

Vygotsky, L. S. (1978). Interaction between learning and development. In M. Cole, V. John-Steiner, S. Scribner, \& E. Souberman (Eds.), Mind in society: The development of higher psychological processes ( $\mathrm{pp}$. 79-91). Cambridge, Massachusetts: Harvard University Press.

The Author is an Assistant Professor of English at Kathmandu University, Nepal. Email: kashiraj@ku.edu.np 